\title{
NIRS measurement of peripheral fractional oxygen extraction (FOE) after cardiopulmonary bypass ${ }^{1}$
} \author{
and Jacques Gerard LeBlanc ${ }^{\mathrm{e}}$ \\ ${ }^{a}$ Department of Child Health, University of Liverpool, United Kingdom \\ ${ }^{\mathrm{b}}$ Department of Paediatrics, University of Ottawa, Ottawa, Canada \\ ${ }^{\mathrm{c}}$ Department of Paediatrics, University of British Columbia, Canada \\ d British Columbia's Children's Hospital, Vancouver, Canada \\ ${ }^{\mathrm{e}}$ Department of Surgery, University of British Columbia, Canada
}

Charles William Yoxall a ${ }^{\text {a }}$ Kusum Menon ${ }^{\mathrm{b}}$, Andrew John Macnab ${ }^{\mathrm{c}, *}$, Roy Everett Gagnon ${ }^{\mathrm{d}}$

\begin{abstract}
Objectives: To compare peripheral fractional oxygen extraction (FOE), as measured by near infrared spectroscopy (NIRS), with conventional indicators of tissue perfusion in haemodynamically stable and unstable children after cardiopulmonary bypass. Design: Observational study. Setting: Paediatric Intensive Care Unit of a large teaching hospital. Patients: 17 children immediately after cardiopulmonary bypass. Male : female $=9: 8$, median age 7 months (range, newborn to 16 years). Methods: On admission, children were classified as "stable" or "unstable" based on the haemodynamic support they needed. Peripheral venous oxyhaemoglobin saturation $\left(\mathrm{SvO}_{2}\right)$ was measured non-invasively using NIRS with venous occlusion. FOE was calculated from $\mathrm{SvO}_{2}$ and arterial saturation measured by pulse oximetry. Repeated measurements of peripheral $\mathrm{SvO}_{2}$ were made for up to 8 hours. In 5 children who had pulmonary artery catheters, simultaneous mixed $\mathrm{SvO}_{2}$ measurements were recorded. Results: Median FOE was 7.9\% higher in the unstable group than in the stable group $(p=0.013)$. Peripheral $\mathrm{SvO}_{2}$ and mixed $\mathrm{SvO}_{2}$ were correlated $\left(R^{2}=0.65, p<0.0001\right)$. Conclusions: Peripheral FOE is higher in unstable children. Changes in peripheral $\mathrm{SvO}_{2}$ are related to changes in mixed $\mathrm{SvO}_{2}$. These measurements may provide useful information about haemodynamic status in critically ill children. Further evaluation of the technique is warranted.
\end{abstract}

Keywords: Near infrared spectroscopy, venous oximetry, tissue oxygenation, cardiopulmonary bypass

\section{Introduction}

Supplying adequate oxygen to the tissues is of central importance during the care of critically ill patients. Although the supply of oxygen has such relevance physiologically, currently physicians have to base treatment decisions predominantly on subjective clinical observations.

Objective data about venous oxygenation provides useful information about the adequacy of tissue oxygenation, since it is a function of the relationship between the rate of oxygen delivery to the tissues and the consumption of oxygen by the tissues. From the venous oxygen saturation, the fractional oxy-

\footnotetext{
${ }^{1}$ Work performed at Paediatric Intensive Care Unit, British Columbia's Children's Hospital, Vancouver, British Columbia, Canada.

*Corresponding author: Dr. Andrew Macnab, Critical Care Physician's Office, 2L10, Children's and Women's Health Centre of British Columbia, 4480 Oak Street, Vancouver, B.C., Canada V6H 3V4. Tel.: +1 604875 3524; Fax: +1 604875 5136; E-mail: amacnab@cw.bc.ca.
} 
gen extraction (FOE), the ratio of the oxygen delivered to the tissues to the amount consumed, can be calculated. FOE can be calculated from:

$$
\mathrm{FOE}=\left(\mathrm{CaO}_{2}-\mathrm{CvO}_{2}\right) / \mathrm{CaO}_{2},
$$

where $\mathrm{CaO}_{2}=$ arterial oxygen content and $\mathrm{CvO}_{2}=$ venous oxygen content. As, under normal physiological oxygen tensions, most of the oxygen in blood is bound to haemoglobin this equation can be simplified to:

$$
\mathrm{FOE}=\left(\mathrm{SaO}_{2}-\mathrm{SvO}_{2}\right) / \mathrm{SaO}_{2}
$$

where $\mathrm{SaO}_{2}=$ arterial oxyhaemoglobin saturation and $\mathrm{SvO}_{2}=$ venous oxyhaemoglobin saturation.

Fibre-optic pulmonary artery catheters use the principle of FOE and can therefore be used to monitoring mixed venous oxyhaemoglobin saturation [1]. However, such monitoring is highly invasive, technically difficult and has potentially serious complications.

An alternative approach is to monitor blood flow in peripheral vascular beds because, when the circulation is impaired, there is redistribution of blood flow away from the gut (splanchnic bed) and peripheral circulation to the heart and brain to maintain myocardial and cerebral oxygenation. Therefore, we hypothesized that monitoring the oxygenation of peripheral tissues would be a sensitive method for detecting adequacy of systemic oxygenation. This hypothesis is supported by studies that have monitored subcutaneous or muscle oxygen tension invasively. These studies have shown that oxygenation in peripheral tissues declines early during the course of shock and recovers late during resuscitation [2, $4,10]$. We developed a method for the non-invasive measurement of $\mathrm{SvO}_{2}$ in the peripheral circulation using near infrared spectroscopy (NIRS) with venous occlusion that has proved to be a useful method for monitoring oxygenation in haemodynamically unstable and anaemic patients $[13,14,16]$.

Near infrared spectroscopy is a non-invasive optical technique that uses the absorption of near infrared light transmitted through the tissues to calculate changes in tissue concentrations of oxyhaemoglobin $\left(\mathrm{HbO}_{2}\right)$ and deoxyhaemoglobin $(\mathrm{Hb})$ [5]. When venous blood flow is occluded, NIRS shows a rise in tissue haemoglobin concentration due to venous engorgement. The rise in tissue haemoglobin content comprises an $\mathrm{HbO}_{2}$ component and a $\mathrm{Hb}$ component. Since the increase in tissue haemoglobin concentration is solely due to an increase in the amount of venous blood, $\mathrm{SvO}_{2}$ can be calculated from the increase in $\mathrm{HbO}_{2}$ as a proportion of the total increase in haemoglobin concentration $\left(\mathrm{HbO}_{2}+\mathrm{Hb}=\mathrm{THb}\right)$. Usually one of the limitations of measurements made with NIRS is that the optical pathlength is required to calculate absolute values, and pathlength is not measured by currently-available NIRS equipment. Because our technique relies on the ratio of the change in $\mathrm{HbO}_{2}$ concentration to the change in $\mathrm{THb}$ concentration during venous engorgement, absolute quantification of the changes is not required, and therefore $\mathrm{SvO}_{2}$ can be measured without reference to optical pathlength.

\section{Materials and methods}

This project was approved by the Clinical Screening Committee for Research Involving Human Subjects at the University of British Columbia and the Research Review Committee of the hospital. Informed consent was obtained from the parents of each child. 
Subjects were 17 children who underwent cardiopulmonary bypass for surgical treatment of congenital heart disease, 7 males and 8 females, median age 7 months, range newborn to 16 years. Four patients had repair of a secundum atrial septal defect, 2 had repair of a ventricular septal defect, 1 had repair of an endocardial cushion defect, 5 had modified Fontan procedures for treatment of complex cyanotic cardiac defects, 3 had arterial switch procedures for treatment of transposition of the great arteries 1 had an aortic valve replacement and 1 had a Norwood procedure for repair of hypoplastic left heart syndrome. Six children had fibre-optic pulmonary catheters positioned during by-pass for post-operative monitoring (Oximetrix 3, Abbott Laboratories, Chicago, IL, USA).

NIRS measurement method: NIRS optodes (the light emitter and receiver at the ends of the fibre optic cables) were placed over the muscles of the forearm and covered with a light-occluding blanket. In infants less than three months old the optodes were positioned on the front and back of the forearm. In older children, optodes were positioned along the long axis of the forearm, on the flexor surface, $3 \mathrm{~cm}$ apart. The NIRS equipment used was a NIRO 500 (Hamamatsu Photonics, Hamamatsu K.K.). This system uses previously published absorption spectra and algorithms to calculate changes in haemoglobin concentration from light absorbance [15]. Sample interval was set to 0.5 seconds. Venous occlusion was achieved by low pressure ( 20 to $30 \mathrm{mmHg}$ ) inflation of a sphygmomanometer cuff about the upper arm for 5 seconds. Arterial saturation was measured by a pulse oximeter (Nellcor N-200, Nellcor Inc. Hayward, CA, USA) modified for 0.5 second collection. The NIRS and pulse oximetry data were recorded in real time in computer files for later analysis using software developed by us for this project. This software was validated by comparing the results on one data set with that obtained using a QuattroPro 6.0 spreadsheet analysis (the usual method) on the same data set.

Method: Measurements of peripheral FOE were begun immediately following transfer to the paediatric intensive care unit from the operating room. At the time of admission, subjects were classified as stable (receiving one or no inotropic agents to support blood pressure and not requiring blood transfusion) or unstable (receiving two or more inotropic agents and/or receiving blood transfusion).

Measurements of peripheral $\mathrm{SvO}_{2}$ were repeated at 15-minute intervals until the patient reached haemodynamic stability, as determined by the patient's attending physician, or for up to 8 hours. Mixed $\mathrm{SvO}_{2}$ was also recorded every 15 minutes in the patients with pulmonary artery catheters. One patient who had pulmonary artery monitoring had a residual ventricular septal defect so the data were unsuitable for comparison.

Heart rate, mean arterial blood pressure and arterial oxygen saturation were recorded continuously on all subjects. Drugs administered and their infusion rates, as well as the timing and rate of blood or colloid infusion were recorded. Data were also obtained from standard clinical monitoring, including core-peripheral temperature gradient, central venous pressure, pulmonary artery pressure or left atrial pressure, haemoglobin concentration and blood gas measurements.

Statistical analysis: The stable and unstable groups were compared based on their FOE on admission using a Mann-Whitney $U$ test. The relationship between mixed $\mathrm{SvO}_{2}$ and peripheral $\mathrm{SvO}_{2}$ was assessed using analysis of covariance [3] using SPSS for Windows 6.1 statistical analysis package.

\section{Results}

A satisfactory NIRS signal could not be obtained in two of the 17 subjects: one subject was extubated immediately and was uncooperative; one was a very poorly perfused older subject (aged 16), in whom there was marked noise in the NIRS signal. 


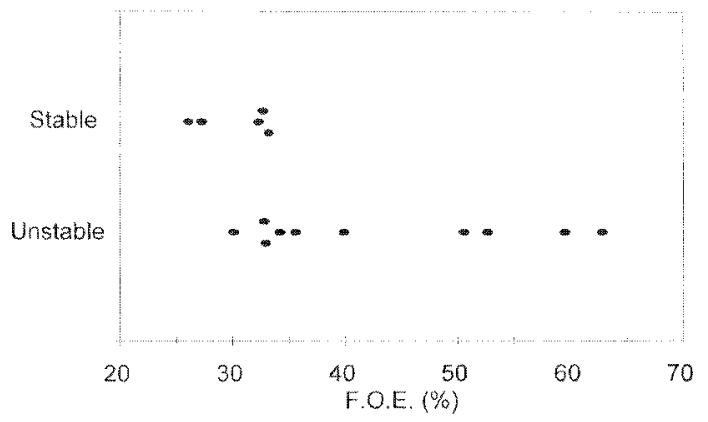

Fig. 1. Fractional oxygen extraction (FOE) on admission for each subject, by group.

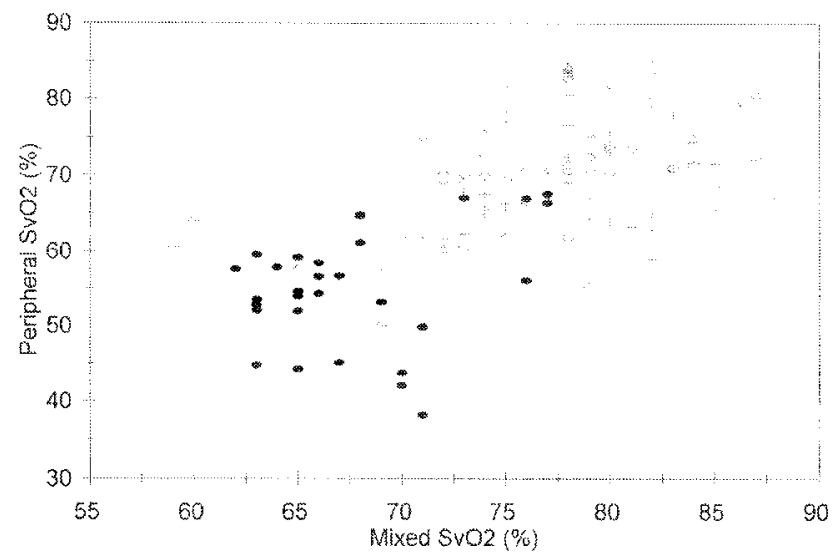

Fig. 2. Peripheral $\mathrm{SvO}_{2}$ plotted against Mixed $\mathrm{SvO}_{2}$ for the five subjects who had relevant pulmonary artery catheter data. Each subject is represented by a different marker.

Median $\mathrm{SvO}_{2}$ for the remaining 15 subjects on admission was $64.3 \%$ (range 36.8 to $72.7 \%$ ). Median FOE for all subjects on admission was $33.2 \%$ (range 26.1 to $62.8 \%$ ). FOE for each subject by group is shown in Fig. 1. FOE was higher in the unstable group, with a difference in the median values between the two groups of $7.9 \%$ ( $95 \%$ confidence interval 26.8 to $0.6 \%$ ), $p=0.013$.

Figure 2 shows a plot of peripheral $\mathrm{SvO}_{2}$ against mixed $\mathrm{SvO}_{2}$ for the five subjects with pulmonary artery catheter data. The analysis of variance for each patient is shown in Table 1 . There was a significant positive relationship between peripheral and mixed $\mathrm{SvO}_{2}$ (adjusted $R^{2}=0.65, p<0.001$ ).

Two sets of data, one from a haemodynamically stable patient and one with a period of instability, are presented in Figs 3 and 4.

\section{Discussion}

$\mathrm{SvO}_{2}$ and $\mathrm{FOE}$ can be measured non-invasively in the peripheral circulation of haemodynamically unstable children. The measurements of FOE made on admission to the intensive care unit after cardiopulmonary bypass showed that higher values were seen in the unstable group. The difference in FOE between the two groups is due to a "tail" of measurements with an FOE greater than $35 \%$ in the unstable group. These tended to be the sickest individuals and included a child who died in the first hour 


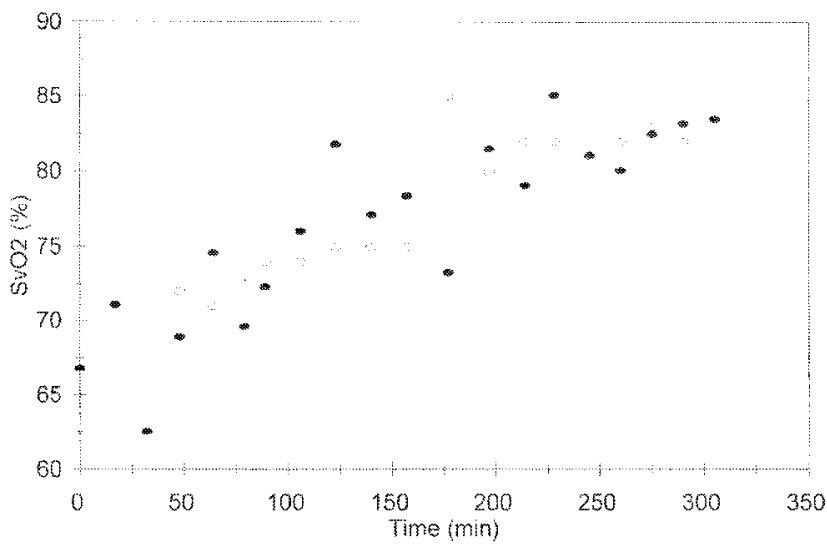

Fig. 3. Changes in peripheral $\mathrm{SvO}_{2}$ and mixed $\mathrm{SvO}_{2}\left(\bigcirc=\right.$ Mixed $\mathrm{SvO}_{2}, \bullet=$ Peripheral $\left.\mathrm{SvO}_{2}\right)$ in one subject who had a steady rise in mixed $\mathrm{SvO}_{2}$, indicating sustained improvement in haemodynamic status. Peripheral $\mathrm{SvO}_{2}$ showed the same steady rise.

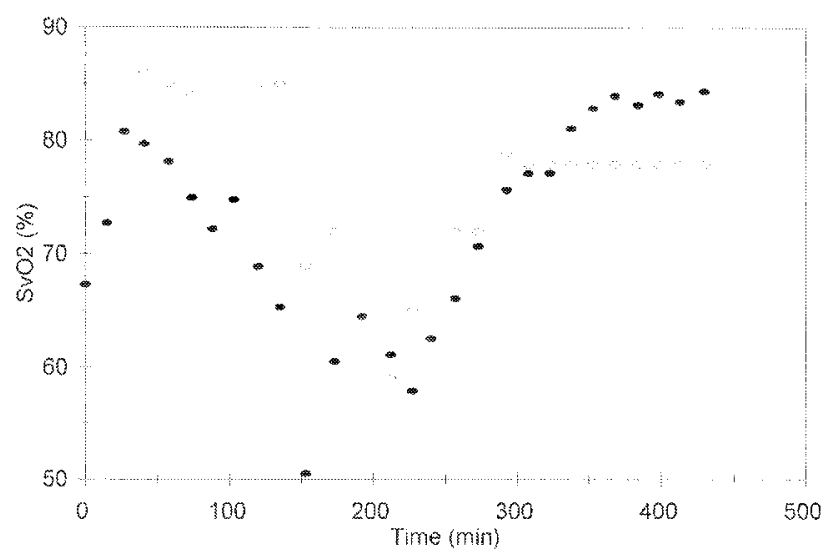

Fig. 4. Changes in peripheral $\mathrm{SvO}_{2}$ and mixed $\mathrm{SvO}_{2}\left(\bigcirc=\right.$ Mixed $\mathrm{SvO}_{2}, \bullet=$ Peripheral $\left.\mathrm{SvO}_{2}\right)$ in one subject who was stable initially but had a pulmonary hypertensive crisis at 2 hours. There was a fall in mixed $\mathrm{SvO}_{2}$ at this time, with an increase as the patient was stabilised over the subsequent 2 hours. Peripheral $\mathrm{SvO}_{2}$ showed the same dramatic fall with a subsequent rise.

$(\mathrm{FOE}=59.5 \%)$. A higher FOE implies that a greater proportion of the oxygen being delivered to the tissues is being consumed by tissue metabolism. It is likely that following surgery involving cardiopulmonary bypass a higher FOE was seen in the unstable group because ongoing circulatory impairment was restricting oxygen delivery to the peripheral tissues.

Analysis of the relationship between peripheral $\mathrm{SvO}_{2}$ and mixed $\mathrm{SvO}_{2}$ showed a significant positive correlation. Trends seen in the mixed $\mathrm{SvO}_{2}$ data with time were also seen in the peripheral $\mathrm{SvO}_{2}$ data. Too few subjects in this study had oximetric pulmonary artery cathers for statistical analysis to be performed on this observation. The implication of these observations is that non-invasive monitoring of peripheral $\mathrm{SvO}_{2}$ may provide qualitative information about the adequacy of tissue oxygenation that is of similar value to that obtained with invasive measurements made in the pulmonary artery. The clinical role of pulmonary artery oximetry in intensive care is widely debated and has been questioned by several groups $[8,9]$, particularly in view of its invasive nature and recognized risks. Some believe that mixed $\mathrm{SvO}_{2}$ monitoring does not contribute to clinical decision-making, but these opinions are based on studies in a population for which information from invasive monitoring was also available to the clinicians. Because 
of the non-invasive nature of peripheral $\mathrm{SvO}_{2}$ measurement, this form of monitoring can probably be applied more widely than invasive monitoring is currently. Consequently, there may be more opportunity for the data provided to contribute to important clinical decision making, with little risk to the patient.

This is a small data set but the results suggest that non-invasive monitoring of peripheral $\mathrm{SvO}_{2}$ monitoring may provide clinically useful information, predominantly about tissue oxygenation in children. Our data also support the impressions of other investigators who have used NIRS to assess adequacy of perfusion during resuscitation from shock. Rhee et al. showed, in a rabbit model of haemorrhagic shock, that cellular oxygenation as measured by NIRS, was not uniformly restored, in spite of normalization of traditional resuscitation parameters [12]. Fortune et al. compared tissue oxygenation indices of cerebral and splanchnic tissue to detect splanchnic ischaemia in newborn infants [7]. Cohn et al. used direct measurement of tissue oxygen saturation using a side-illuminating NIRS gastric probe to monitor change in splanchnic perfusion in swine following experimentally-induced haemorrhage [6]. Rasmussen et al. used NIRS to monitor liver and splanchnic blood flow during progressive haemorrhage in pigs [11]. In studies evaluating the medical management of preterm infants with hypotension, FOE remained unchanged [14]. However, in anaemic preterm infants FOE values were higher in babies with symptomatic anaemia than those with asymptomatic anaemia, and the high FOE values among symptomatic babies decreased after transfusion [13].

\section{Conclusion}

Peripheral FOE is higher in unstable children. Changes in peripheral $\mathrm{SvO}_{2}$ are related to changes in mixed $\mathrm{SvO}_{2}$. These measurements may provide useful information about haemodynamic status in critically ill children. Overall, further evaluation of near infrared spectroscopy as a means of non-invasively assessing the adequacy of resuscitation and perfusion in human subjects appears to be warranted.

\section{Acknowledgements}

We are grateful for the support of the International Paediatric Research Foundation (CWY) and the British Columbia Lung Association (career support AJM).

\section{References}

[1] C.C. Aurel and L.D. Nelson, The significance of mixed venous saturation and technical aspects of continuous measurement, in: Oxygen Transport: Principles and Practice, J.D. Edwards, W.C. Shoemaker and J.L. Vincent, eds, W.B. Saunders, London, 1993, pp. 70-98.

[2] G.I. Beerthuizen, R.J. Goris and F.J. Kreuzer, Skeletal muscle $\mathrm{PO}_{2}$ during imminent shock, Arch. Emerg. Med. 6 (1989), $72-82$.

[3] J.M. Bland and D.G. Altman, Calculating correlation coefficients with repeated observations: Part 1 - correlation within subjects, BMJ 310 (1995), 446.

[4] J.W. Brantigan, E.C. Ziegler, K.M. Hynes, T.Y. Miyazawa and A.M. Smith, Tissue gasses during hypovolaemic shock, J. Appl. Physiol. 37 (1974), 1217-1224.

[5] J.E. Brazy, Near infrared spectroscopy, Clin. Perinat. 3 (1991), 519-533.

[6] S.M. Cohn, J.E. Varela, G. Giannotti, M.O. Dolich, M. Brown, A. Feinstein, M.G. McKenney and P. Spalding, Splanchnic perfusion evaluation during haemorrhage and resuscitation with gastric near infrared spectroscopy, J. Trauma 50(4) (2001), 629-634.

[7] P.M. Fortune, M. Wagstaff and A.J. Petros, Cerebro-splanchnic oxygenation ratio (CSOR) using near infrared spectroscopy may be able to predict splanchnic ischaemia in neonates, Intens. Care Med. 27(8) (2001), 1401-1407. 
[8] M.S. Jastremski, L. Chelluri, K.M. Beney and R.T. Bailly, Analysis of the effects of continuous on-line monitoring of mixed venous oxygen saturation on patient outcome and cost-effectiveness, Crit. Care Med. 17 (1989), 148-152.

[9] K.S. Pearson, M.N. Gomez, J.R. Moyers, J.G. Carter and J.H. Tinker, A cost/benefit analysis of randomised invasive monitoring for patients undergoing cardiac surgery, Anest. Analg. 69 (1989), 336-341.

[10] C.C. Powell, S.C. Schultz, D.G. Burris, W.R. Drucker and D.S. Malcolm, Subcutaneous oxygen tension: A useful adjunct in assessment of perfusion status, Crit. Care Med. 23 (1995), 867-873.

[11] A. Rasmussen, C. Skak, M. Kristensen, P. Ott, P. Kirkegaard and N.H. Secher, Preserved arterial flow secures hepatic oxygenation during haemorrhage in the pig, J. Physiol. 15(516 Pt 2) (1999), 539-548.

[12] P. Rhea, L. Langdale, C. Mock and L.M. Gentilello, Near infrared spectroscopy: continuous measurement of cytochrome oxidation during haemorrhagic shock, Crit. Care Med. 25(1) (1997), 166-170.

[13] S.P. Wardle, C.W. Yoxall, E. Crawley and A.M. Weindling, Peripheral oxygenation and anaemia in pre-term babies, Pediatr. Res. 44(1) (1998), 125-131.

[14] S.P. Wardle, C.W. Yoxall and A.M. Weindling, Peripheral oxygenation in hypotensive preterm babies, Pediatr. Res. 45(3) (1999), 343-349.

[15] S. Wray, M. Cope, D.T. Delpy, J.S. Wyatt and E.O.R. Reynolds, Characterisation of the near infrared absorption spectra of cytochrome aa3 and haemoglobin for the monitoring of cerebral oxygenation, Biochim. Biophys. Acta 933 (1988), 184-192.

[16] C.W. Yoxall and A.M. Weindling, The measurement of peripheral venous oxyhaemoglobin saturation in newborn infants with near infrared spectroscopy with venous occlusion, Paediatr. Res. 39 (1996), 1103-1106. 


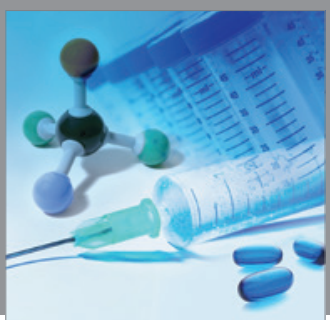

International Journal of

Medicinal Chemistry

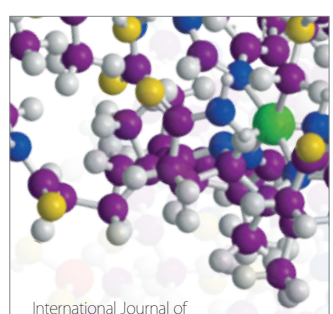

Carbohydrate Chemistry

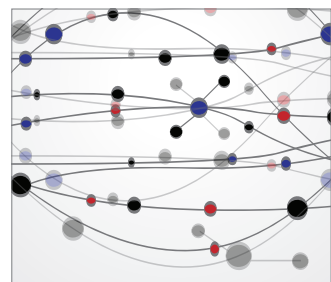

The Scientific World Journal
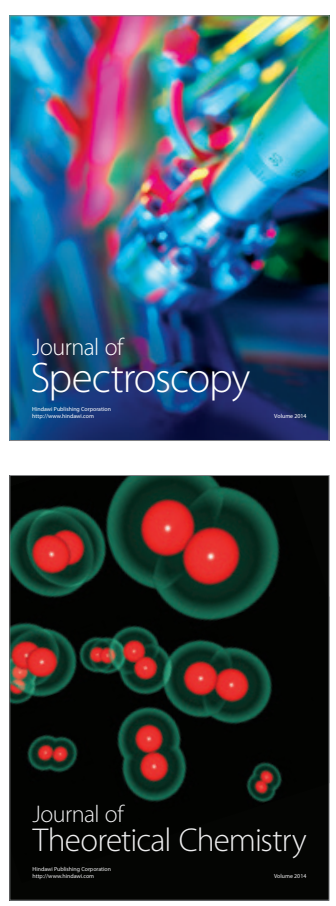
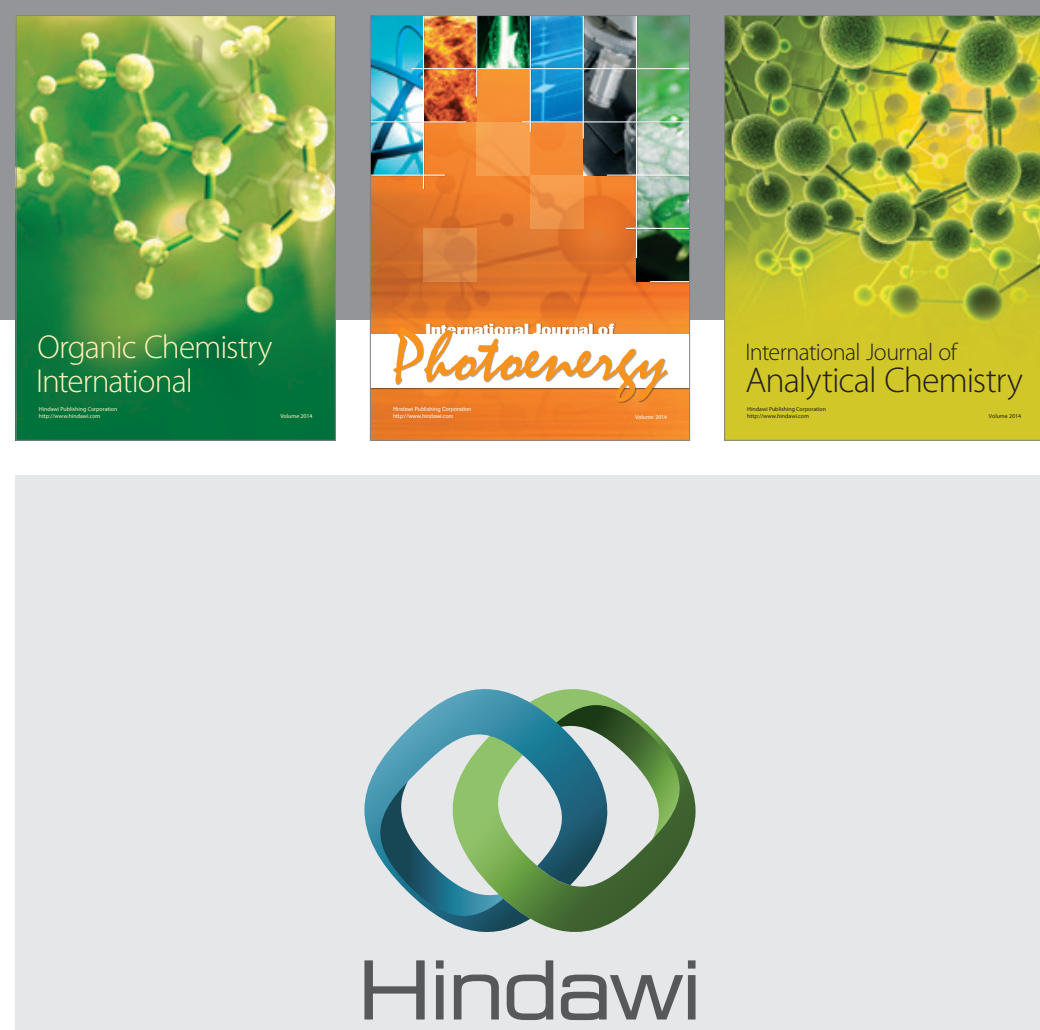

Submit your manuscripts at

http://www.hindawi.com
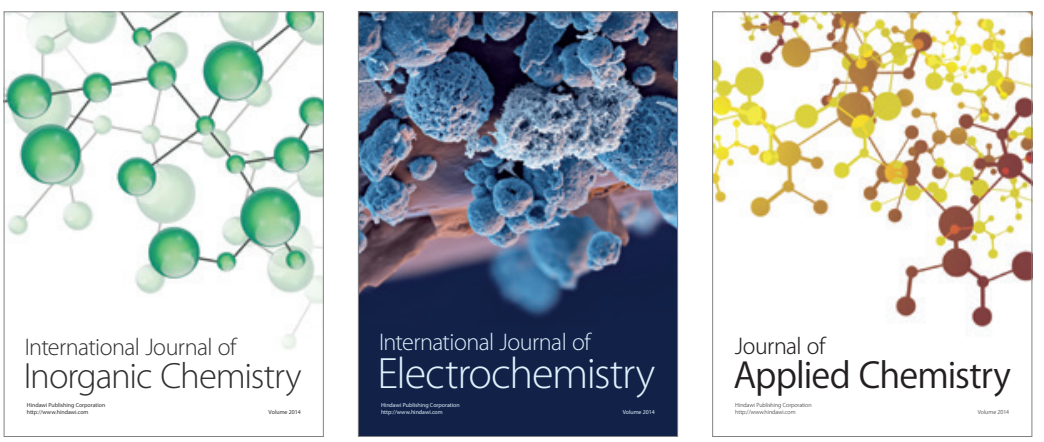

Journal of

Applied Chemistry
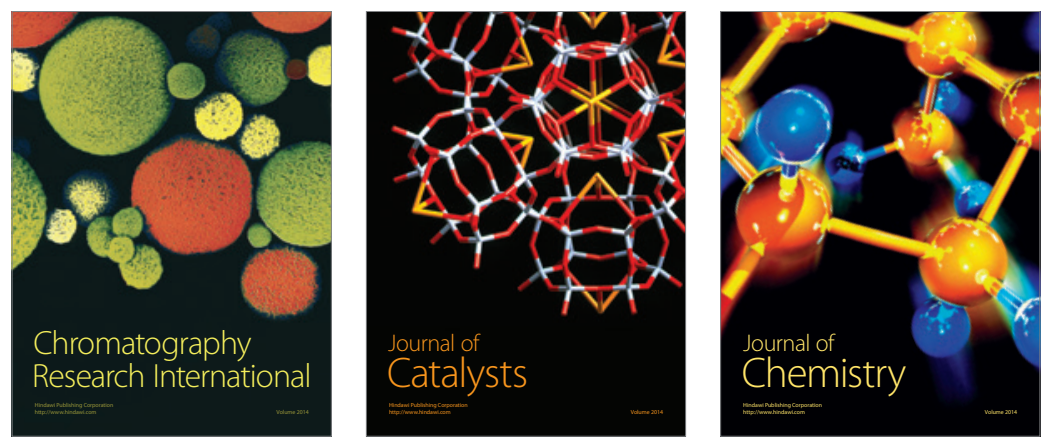
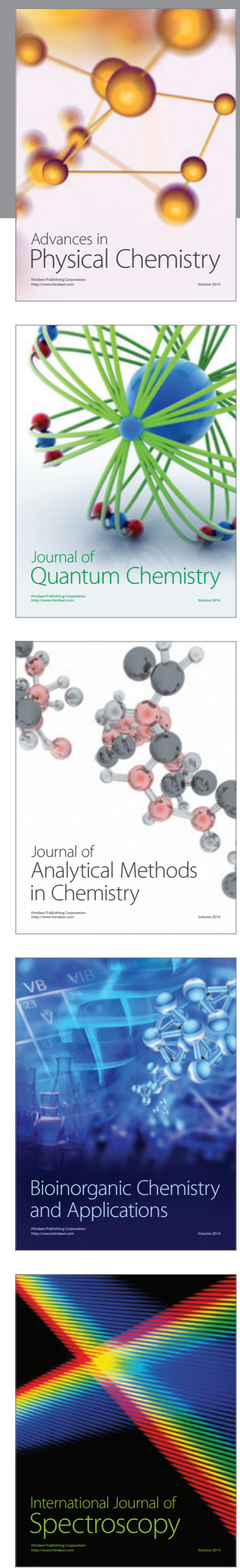